\title{
Hulusi Behçet (1889-1948): Passion for dermatology
}

\author{
Siang Yong $\underline{T a n}^{1}$, MD, JD, Patricia Sims $\underline{\text { Poole }}^{2}$, MD
}

$\mathrm{H}$ ulusi Behçet was a Turkish clinician who did not win a Nobel Prize or become the Dean of a prominent medical school. Still, he stands at the forefront of medical history, with an exotic disease bearing his name - Behçet's disease or syndrome. His diligence and passion for dermatology opened the world's eyes to this old, yet unrecognised, tortuous disease, which is characterised by its famous triad of oral and genital ulcerations as well as ocular inflammation.

CHILDHOOD AND MEDICAL TRAINING Behçet was born in Istanbul, part of what is now Turkey, on 20 February 1889. At that time, the city was known as Constantinople and was part of the Ottoman Empire. His mother, Ayşe Behçet, was the first cousin of his father, Ahmet Behçet; their marriage was arranged by traditional matchmaking. Behçet's mother died when he was a young boy and he was raised by his grandmother. His was a gloomy and difficult childhood, which may have contributed to his introversion in adulthood.

At a young age, Behçet moved to Damascus because of his father's business affairs. In 1516, Damascus was absorbed into the Ottoman Empire, which would rule the city for four centuries. Political stability and the city's increasing importance along several trade routes made it attractive to business, and the city gained a cosmopolitan air. Behçet thrived in

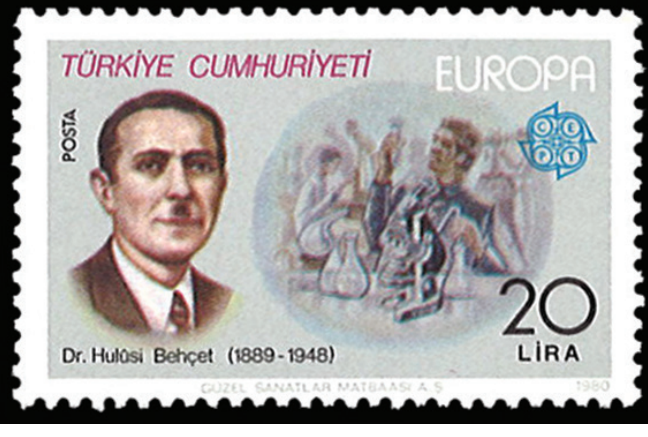

medical education, and medical colleges began to prioritise scientific endeavour. These reforms led to the establishment of Istanbul University. In 1933, Behçet became the director of its Department of Dermatology and Venereal Diseases; he would remain there until 1947. He also became one of the first medical professors in all of Turkey.

THE DISCOVERY The work for which Behçet is best known had its origin in three patients he encountered as a clinical dermatologist. The first, whom he saw from 1924 to 1925, had previously visited a myriad of physicians in Istanbul and Vienna, Austria, over the course of some 40 years without a diagnosis being made. The patient had completely lost his vision by the time he visited Behçet. Diagnostic considerations included everything from syphilis to tuberculosis to an unknown protozoal disease. Behçet next saw a woman in 1930 with similar complaints of recurrent irritation in her eyes, and lesions in her mouth and genital regions. A biopsy was non-diagnostic. In 1936, Behçet examined yet another patient with eye inflammation, oral and scrotal ulcers, evening fever, and abdominal pain. Putting the symptoms together, Behçet theorised that they were protean manifestations of a specific disease, possibly caused by a virus. He published these cases in the Archives of Dermatology and Venereal Disease in 1937. Physicians from Belgium, Italy, his elementary studies in a French-speaking school, learning French, Latin and German. In 1906, at the age of 16, Behçet started his medical education at Kuleli Military Medical School, graduating in 1910. He developed an interest in skin disorders and received specialised training in dermatology and venereal diseases at Gülhane Military Hospital. In 1914, Behçet completed his training and went on to work as a consultant dermatologist at Edirne Military Hospital for the next four years.

In order to bypass the religious and political agendas of his country that he believed kept the medical field from advancing, Behçet moved to France's famous Charité hospital, one of Europe's foremost centres of medicine. However, his stay there was short-lived; Behçet soon returned to his native Turkey to work as a private dermatologist in a local district that was endemic for an unusual disease, one that would subsequently bear his name. Given his credentials and clinical experience, he soon gained an appointment at Guraba Hospital, a close affiliate of Istanbul Medical College. The establishment of the Turkish Republic in 1923 resulted in many social reforms, including changes in
Austria, the United States, Japan, Denmark, Switzerland and Israel soon began reporting similar cases. Finally, at the International Congress of Dermatology in Geneva on 13 September 1947, the medical world acknowledged Behçet's observations as being pathognomonic of a new disease. Dr Miescher, a dermatology professor at the University of Zurich Medical School, proposed that the disease be named 'Morbus Behçet' (Behçet's disease).

In truth, Behçet was not the very first to describe the condition. It was referenced in the writings of Hippocratic physicians in the fifth century BC: "There were other forms of fever..., many had their mouths affected with aphthous ulcerations. There were also many defluxions about the genital parts, and ulcerations, boils (phymata), externally and internally about the groins. Watery ophthalmies of a chronic character, with pains; fungous excretions of the eyelids externally and internally, called fici, which destroyed the sight of many persons." In 1922, two investigators, Planner and Remenovsky, reported a case suggestive of Behçet's disease. In 1930, Dr Benediktos Adamantiades, a Greek ophthalmologist, described a patient with relapsing iritis

${ }^{1}$ Emeritus Professor of Medicine, University of Hawaii, ${ }^{2}$ Research carried out during Transitional Residency, Hawaii Residency Programs Inc, Honolulu, Hawaii, USA Correspondence: Prof Tan Siang Yong, 2226 Liliha Street, Suite B-104, Honolulu, HI 96817, USA. siang@hawaii.edu 
and hypopyon, accompanied by arthritis and mucocutaneous symptoms. However, like many others, he failed to ascribe the signs and symptoms to a new or single syndrome and missed the distinctive classic triad. Nevertheless, Behçet credited Dr Adamantiades' work in his original publication and Behçet's syndrome is sometimes referred to as the 'Adamantiades-Behçet syndrome'.

THE DISEASE To this day, the cause of Behçet's syndrome remains ill-defined, but it is believed to be an autoimmune vasculitis with a predilection for certain organs. The disease is strongly associated with HLA-B51 and is most prevalent in the Middle East and Central Asia. A viral aetiology remains unproven. The traditional Behçet's triad has been modified and, according to the International Study Group's guidelines, contains oral ulcers as a required criterion, with two other criteria (out of four) being required to clinch the diagnosis. These criteria are genital ulcers, assorted skin lesions, ophthalmitis and a positive pathergy reaction (skin papule eruption of $>2 \mathrm{~mm}$ diameter, 24 to 48 hours after a needle-prick). This enigmatic condition can affect multiple organ systems such as the joints, heart, intestinal tract, vascular system, skin and central nervous system. It runs a chronic course with unpredictable exacerbations and remissions that often leave the patient completely debilitated. Involvement of the blood vessels supplying the optic nerve is believed to be the cause of optic atrophy and blindness in Behçet's disease. Therapy is symptomatic and includes high-dose steroids and immunosuppressants such as anti-tumour necrosis factor drugs, interferon and thalidomide.

PERSONAL LIFE AND ACCOMPLISHMENTS Behçet spent an inordinate amount of his life travelling. His passion for dermatology and education led him to many a national and international medical congress. He published widely, producing in toto about 137 scientific papers, two medical books, 12 monographs and 17 medical translations, and had an unending influence on the future of Turkish medicine, as he translated many articles into the Turkish language. A notable legacy was his 1940 monograph, Clinical and Practical Syphilis, Diagnosis and
Related Dermatoses. Behçet had been interested in syphilis since his early training and published many articles on its diagnosis and treatment. This monograph was a masterly compilation of every aspect of the disease, including its differential diagnosis, as known at the time.

Although Behçet's greatest achievements were in the realm of medicine, he was equally passionate about the arts and literature. He was a shy, introverted man due to his rough childhood, but was described as being joyful and good-humoured among his close friends. Still, he was of a nervous disposition and suffered from chronic insomnia, colitis and angina pectoris. In 1923, not long after he moved back to Turkey, Behçet fell in love with and married Refika Davaz, the sister of one of his patients. As his new bride was the daughter of a famous diplomat, Behçet began to accept many patients from Istanbul's high society. Together they had their only daughter, Güler. Unfortunately, the marriage ended in divorce in 1941, just seven years before his sudden death at age 59 from a heart attack.

\section{BIBLIOGRAPHY}

- Behçet H. [Über rezidivierende, aphtöse, durch ein Virus verursachte Geschwüre am Mund, am Auge und an den Genitalien]. Dermatologische Wochenschrift 1937; 105:1152-63. German.

- Cheng TO. Behçet Disease, Adamantiades-Behçet Disease, or HippocratesAdamantiades-Behçet Disease? Chest 2002; 122:381-2.

- Cheng TO. Some historical notes on Behçet's disease. Chest 2001; 119:667-8.

- Escudier M, Bagan J, Scully C. Number VII Behçet's disease (Adamantiades syndrome). Oral Dis 2006; 12:78-84.

- Evereklioglu C. Regarding the naming dilemma of Behçet disease in the 21st century. Oral Dis 2007; 13:117-21.

- Onder M, Gürer MA. Behçet's disease: an enigmatic vasculitis. Clin Dermatol 1999; 17:571-6.

- Saylan T. Life story of Dr. Hulusi Behçet. Yonsei Med J 1997; 38:327-32.

- Tirilomis T. Some more historical notes on Adamantiades-Behçet's Disease. Chest 2001; 120:2116.

- Tüzün Y. Hulusi Behçet, MD: February 20, 1889 to March 8, 1948. Clin Dermatol 2006; 24:548-50.

- UStün C. A famous Turkish dermatologist, Dr. Hulusi Behçet. Eur J Dermatol 2002; 12:469-70.

- Zouboulis CC. Benediktos Adamantiades and his forgotten contributions to medicine. Eur J Dermatol 2002; 12:471-4.

- Zouboulis CC, Keitel W. A historical review of early descriptions of Adamantiades-Behçet's disease. J Invest Dermatol 2002; 119:201-5. 